\title{
Unconventional Route to Hairy Plasmonic/Semiconductor Core/Shell Nanoparticles with Precisely Controlled Dimensions and Their Use in Solar Energy Conversion
}

\author{
Dajiang Zheng, ${ }^{\dagger, \dagger}$ Xinchang Pang, ${ }^{\dagger}$ Mengye Wang, ${ }^{\dagger, \dagger}$ Yanjie He, ${ }^{\dagger}$ Changian Lin, ${ }^{*},{ }^{\dagger}$ and Zhiqun Lin ${ }^{*}{ }^{\dagger}$ \\ ${ }^{\dagger}$ School of Materials Science and Engineering, Georgia Institute of Technology, Atlanta, Georgia 30332, United States \\ ${ }^{\ddagger}$ Department of Chemistry, College of Chemistry and Chemical Engineering, Xiamen University, Xiamen 361005, China
}

Supporting Information

ABSTRACT: Atom transfer radical polymerization (ATRP) of 4-vinylpyridine, $t$-butyl acrylate, and styrene in sequential order from a $\beta$-cyclodextrin core yielded an amphiphilic starlike triblock copolymer, poly(4-vinylpyridine)-block-poly(tbutyl acrylate)-block-polystyrene (P4VP-b-PtBA-b-PS). Subsequently, star-like triblock copolymer composed of inner hydrophilic P4VP blocks, central hydrophobic PtBA blocks, and outer hydrophobic PS blocks with well-defined molecular architecture and molecular weight of each block was judiciously exploited as nanoreactor for synthesis of precisely shaped hairy plasmonic/semiconductor $\mathrm{Au} / \mathrm{TiO}_{2}$ core/shell nanoparticles. The resulting $\mathrm{Au} / \mathrm{TiO}_{2}$ nanoparticles were intimately and permanently tethered with outer PS chains that enabled the superior solubility of nanoparticles in nonpolar solvents. The PS chains on the surface of these bifunctional nanoparticles were carbonized by annealing in an inert atmosphere (i.e., yielding carbon-coated $\mathrm{Au} / \mathrm{TiO}_{2}$ nanoparticles). In comparison to a widely used $\mathrm{TiO}_{2}$ network film (i.e., P25)-based device, dye-sensitized solar cells assembled by incorporating a thin layer of carbonized $\mathrm{Au} / \mathrm{TiO}_{2}$ nanoparticles on the top of P25 film as photoanode exhibited largely improved short-circuit current density, $J_{S C}(18.4 \%$ increase), and power conversion efficiency, PCE (13.6\% increase), respectively. Such improvements were attributed to the surface plasmon-enabled light harvesting enhancement of Au core and fast electron transport promoted by the carbon layer coating on $\mathrm{Au} / \mathrm{TiO}_{2}$ nanoparticles, as revealed by external quantum efficiency (EQE), UV-vis spectroscopy, and electrochemical impedance spectroscopy measurements, respectively.

\section{INTRODUCTION}

The ability to control the dimension, composition, crystallinity, and architecture of nanoparticles is of technological importance as the optical, electrical, optoelectronic, catalytic, and magnetic properties of nanoparticles are strongly correlated with these parameters. Significant advances have been made in synthesizing a wide range of nanoparticles with good control over particle size and shape. ${ }^{1}$ They serve as building blocks to construct miniaturized devices with spatially defined structures and unique properties by exquisitely tailoring the assembly and programming the functionalities of building blocks. In comparison to plain nanoparticles, core/shell nanoparticles containing two different nanoscale functionalities affords a platform to modify the properties of nanoparticles. However, high-quality core/shell nanoparticles with controlled dimensions are often prepared by the epitaxial growth of dissimilar materials which allow only moderate lattice mismatch between them $(<2 \%){ }^{2}$ Clearly, it is highly desirable to develop a nonexpitaxial growth strategy for creating precisely controlled spherical core/shell nanoparticles with well-defined core diameter and shell thickness. However, effective strategies to yield such high-quality core/shell nanoparticles are comparatively few and limited in scope.

Metal nanoparticles are the subject of extensive research as they promise new opportunities for use in nonlinear optical switching, catalysis, and surface-enhanced Raman scattering (SERS)-based sensing. ${ }^{3}$ Au nanoparticles with sizes in the range of 5 to $20 \mathrm{~nm}$ display a characteristic collective oscillation frequency of surface plasmon resonance (SPR) with a SPR band at $520 \mathrm{~nm} .{ }^{4}$ Due to the characteristic catalytic, optical, and electronic properties of each constituent, noble metal/semiconductor core/shell nanoparticles have immense potential for applications in catalysis, photocatalysis, sensors, electrode materials, and solar energy conversion. In the latter context, dye-sensitized solar cells (DSSCs) are one of the most promising low-cost alternatives to conventional solid-state devices with relatively high performance. ${ }^{5-14}$ Typically, in DSSCs, dyes are excited to generate excitons (i.e., electron and

Received: April 16, 2015

Revised: July 20, 2015

Published: July 21, 2015 
hole pairs) upon the absorption of photons. Electrons are then injected to the conduction band of a semiconductor film (e.g., $\mathrm{TiO}_{2}$ nanoparticle film), while scavenged by the redox couple, holes transport to the Pt-based counter electrode. Various strategies have emerged to improve the power conversion efficiency of DSSCs, including the effective harnessing of longwavelength solar photons by utilizing new dyes (e.g., quantum dots, cosensitizers, etc.), and the enhancement of light harvesting through the incorporation of plasmonic nanoparticles. $^{15-22}$

Herein, we report a viable strategy based on amphiphilic starlike triblock copolymer as nanoreactor for creating monodisperse $\mathrm{Au} / \mathrm{TiO}_{2}$ core/shell nanoparticles composed of plasmonic $\mathrm{Au}$ core and semiconductor $\mathrm{TiO}_{2}$ shell that can be grown independently. The key to our strategy is the implementation of an amphiphilic nanoreactor, that is, starlike triblock copolymer, poly(4-vinylpyridine)-block-poly( $t$ butyl acrylate)-block-polystyrene (P4VP-b-PtBA-b-PS) synthesized by atom transfer radical polymerization (ATRP) of 4vinylpyridine, $t$-butyl acrylate, and styrene monomers in sequential order from a $\beta$-cyclodextrin-based macroinitiator. The inner hydrophilic P4VP blocks and central hydrophilic poly(acrylic acid) (PAA) blocks transformed from hydrophobic $\mathrm{P} t \mathrm{BA}$ rendered the formation of $\mathrm{Au}$ core and $\mathrm{TiO}_{2}$ shell through coordination interactions between metal moieties of corresponding precursors and functional groups in P4VP and PAA blocks, respectively. This unconventional strategy virtually eliminated the constraint imposed by epitaxial growth that is often a prerequisite for producing high-quality core/shell nanoparticles. On the other hand, the outer hydrophobic PS blocks imparted the outstanding solubility of plasmonic/ semiconductor $\mathrm{Au} / \mathrm{TiO}_{2}$ nanoparticles (forming hairy $\mathrm{Au}$ / $\mathrm{TiO}_{2}$ nanoparticles with PS "hairs") in nonpolar solvents as a result of intimate and permanent capping of PS chains on the surface of $\mathrm{Au} / \mathrm{TiO}_{2}$ nanoparticles. $\mathrm{Au} / \mathrm{TiO}_{2}$ nanoparticles were then incorporated in DSSCs by depositing a thin layer of $\mathrm{Au} /$ $\mathrm{TiO}_{2}$ nanoparticles on the top of commonly used $\mathrm{TiO}_{2}$ photoanode film, resulting in an enhanced device performance (i.e., an $7.4 \%$ increase) owing to light harvesting enhancement enabled by $\mathrm{Au}$ core surface plasmon. Quite intriguingly, the outer PS blocks can be readily carbonized in an inert atmosphere and subsequently acted as a conductive carbon coating on the $\mathrm{Au} / \mathrm{TiO}_{2}$ nanoparticle surface to promote the charge transfer in DSSCs, yielding further improved power conversion efficiency (i.e., a $13.6 \%$ increase).

\section{EXPERIMENTAL SECTION}

2.1. Synthesis of PS-Capped $\mathrm{Au} / \mathrm{TiO}_{2}$ Core/Shell Nanoparticles Composed of Plasmonic Au Core and Semiconductor $\mathrm{TiO}_{2}$ Shell. Central to our strategy for creating uniform core/shell nanoparticle is to synthesize amphiphilic star-like triblock copolymers, poly(4-vinylpyridine)-block-poly(t-butyl acrylate)-block-polystyrene (P4VP-b-PtBA-b-PS), with well-defined molecular architecture and molecular weight of each block that can serve as nanoreactor to yield core/shell nanoparticles. In this regard, first we synthesized 21-arm, star-like P4VP- $b$-P $t$ BA- $b$-PS triblock copolymer with narrow molecular weight distribution of each block by atom transfer radical polymerization (ATRP) of 4-vinylpyridine (4VP), $t$-butyl acrylate $(t \mathrm{BA})$, and styrene $(\mathrm{St})$ in sequential order from a $\beta$-cyclodextrin $(\beta$-CD)-based macroinitiator (i.e., star-like heptakis[2,3,6-tri-O-2-bromo-2-methylpropionyl]- $\beta$-cyclodextrin (21-Br- $\beta$-CD $)$ ) according to our previous work. ${ }^{1,23}$ Briefly, $21-\mathrm{Br}-\beta$-CD macroinitiator was prepared by reacting 21 hydroxyl $(-\mathrm{OH})$ groups on $\beta$-CD with 2 -bromoisobutyryl bromide. ${ }^{23-25}$ ATRP of $4 \mathrm{VP}, t \mathrm{BA}$, and $\mathrm{St}$ was then performed by using bromine-terminated $21-\mathrm{Br}-\beta-\mathrm{CD}$ macroinitiator, yielding 21 -arm star-like P4VP- $b$-P $t$ BA- $b$-PS with precisely tailored molecular weight (upper left panel in Scheme 1). Plasmonic/semiconductor $\mathrm{Au} / \mathrm{TiO}_{2}$

Scheme 1. Schematic Stepwise Representation of the Synthetic Route to PS-Capped $\mathrm{Au} / \mathrm{TiO}_{2}$ Core/Shell Nanoparticles (Lower Central Panel; Denoted $\mathrm{Au} / \mathrm{TiO}_{2}-$ PS) Composed of Plasmonic Au Core and Semiconductor $\mathrm{TiO}_{2}$ Shell by Exploiting Star-Like P4VP- $b$-PtBA- $b$-PS Triblock Copolymer (Upper Right Panel) as Template That Is Synthesized by Sequential ATRP of 4-Vinyl Pyridine, $t$ Butyl Acrylate, and Styrene and Subsequent Thermal Annealing of PS-Capped $\mathrm{Au} / \mathrm{TiO}_{2}$ Core/Shell Nanoparticles in Air and Ar Leads to the Formation of Naked $\mathrm{Au} / \mathrm{TiO}_{2}$ Core/Shell Nanoparticles (Lower Right Panel) and CarbonCoated $\mathrm{Au} / \mathrm{TiO}_{2}$ Core/Shell Nanoparticles (Lower Left Panel; Denoted $\left.\mathrm{Au} / \mathrm{TiO}_{2}-\mathrm{C}\right)$, Respectively

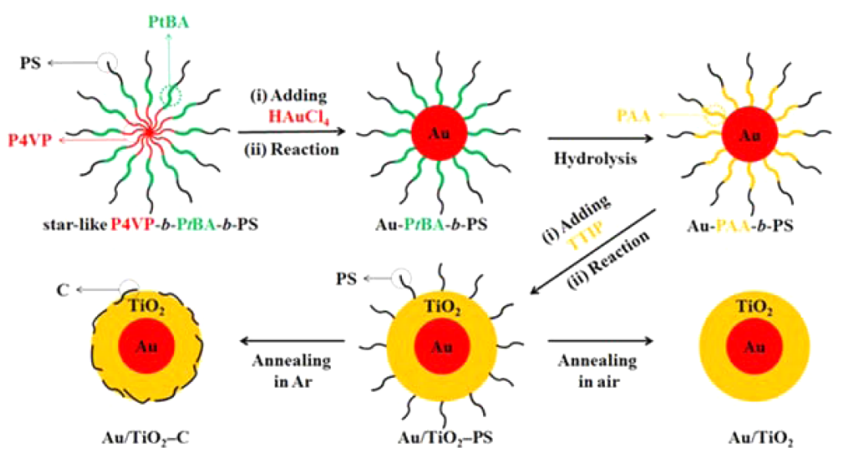

core/shell nanoparticles were then crafted with the formation of $\mathrm{Au}$ core first, followed by the growth of $\mathrm{TiO}_{2}$ shell, by employing star-like P4VP- $b$-PtBA- $b$-PS triblock copolymer as nanoreactor (i.e., template). Specifically, P4VP- $b$-P $t$ BA- $b$-PS template $(10 \mathrm{mg})$ with molecular weights of 13000,8500 , and 6000 for P4VP, PtBA, and PS blocks, respectively, was first dissolved in a mixture of dimethylformamide $(\mathrm{DMF})$ and benzyl alcohol $(\mathrm{BA})$ (volume ratio of $\mathrm{DMF} / \mathrm{BA}=9: 1)$ at room temperature, forming unimolecular micelles of star-like P4VP- $b$ PtBA-b-PS. Au precursor $\mathrm{HAuCl}_{4}(100 \mathrm{mg}$, with ethanol as reducer) was then added to the unimolecular micelle DMF/BA solution. As central PtBA blocks and outer PS blocks are hydrophobic and do not possess reactive functional groups that can coordinate with $\mathrm{Au}^{3+}$ of $\mathrm{HAuCl}_{4}$, the $\mathrm{Au}$ precursors were selectively incorporated into the regime occupied by inner star-like hydrophilic P4VP blocks driven by strong coordination interaction between pyridine groups in $\mathrm{P} 4 \mathrm{VP}$ blocks of unimolecular micelles with $\mathrm{Au}^{3+}$. Subsequent reduction of $\mathrm{Au}^{3+}$ with the presence of ethanol as reducer at $60{ }^{\circ} \mathrm{C}$ for $10 \mathrm{~h}$ produced $\mathrm{Au}$ core nanoparticles directly tethered with $\mathrm{P} t \mathrm{BA}-b$-PS blocks (i.e., PS- $b$-PtBA-capped Au; upper central panel in Scheme 1).

In order to form $\mathrm{TiO}_{2}$ shell, thermal annealing of PS- $b$-P $t \mathrm{BA}$-capped $\mathrm{Au}$ core nanoparticles was carried out to convert the central PtBA blocks into carboxyl group-containing poly(acrylic acid) (PAA) blocks that can act as template (upper right panel in Scheme 1) for synthesis of $\mathrm{TiO}_{2}$ shell. Typically, $\mathrm{TiO}_{2}$ precursor $\mathrm{Ti}\left(\mathrm{OCH}\left(\mathrm{CH}_{3}\right)_{2}\right)_{4}$ (TTIP, 100 $\mathrm{mg}$ ) was added to the PAA- $b$-PS-capped Au core nanoparticles DMF/ $\mathrm{BA}(9 / 1)$ solution, yielding $\mathrm{TiO}_{2}$ shell via the coordination interaction between the carboxyl groups of PAA blocks and the metal moieties of TTIP at $180^{\circ} \mathrm{C}$ under argon for $2 \mathrm{~h}$. The resulting bifunctional $\mathrm{Au} /$ $\mathrm{TiO}_{2}$ core/shell nanoparticles have a $\sim 15 \mathrm{~nm}$ plasmonic Au core and $\sim 5 \mathrm{~nm}$ thick semiconductor $\mathrm{TiO}_{2}$ shell with intimately and permanently tethered hydrophobic PS blocks on the surface that facilitated the solubility and dispersity of nanoparticles in a large variety of nonpolar solvents (lower central panel in Scheme 1).

2.2. Assembly of Dye-Sensitized Solar Cells with Carbonized $\mathrm{Au} @ \mathrm{TiO}_{2}$ Layer. Homemade P25 paste was used to fabricate the $\mathrm{TiO}_{2}$ nanoparticle film as photoanode. First, the P25 paste was coated on the FTO glass using doctor-blade and then annealed at $500{ }^{\circ} \mathrm{C}$ in air for $2 \mathrm{~h}$. After cooling down, an $\mathrm{Au} / \mathrm{TiO}_{2}-\mathrm{PS}$ (i.e., PS-capped $\mathrm{Au} /$ 
$\mathrm{TiO}_{2}$ core/shell nanoparticles) toluene solution was spin-coated on the $\mathrm{TiO}_{2}$ (i.e., P25) film, yielding a monolayer thick nanoparticle coating on the P25 film surface. Subsequently, it was then annealed at $500{ }^{\circ} \mathrm{C}$ in air (converting PS-capped $\mathrm{Au} / \mathrm{TiO}_{2}$ into naked $\mathrm{Au} / \mathrm{TiO}_{2}$ nanoparticles (lower right panel in Scheme 1)) or argon (converting PS-capped $\mathrm{Au} / \mathrm{TiO}_{2}$ into carbon-capped $\mathrm{Au} / \mathrm{TiO}_{2}$ nanoparticles (lower left panel in Scheme 1); i.e., carbons situated on the surface of $\mathrm{Au} / \mathrm{TiO}_{2}$ nanoparticles) for $1 \mathrm{~h}$. We note that as P25 film may exist some small fraction of unoccupied spaces between adjacent $\mathrm{TiO}_{2}$ film (e.g., cracks and defects), due to solvent evaporation after bladecoating, and some PS-capped and carbon-capped $\mathrm{Au} / \mathrm{TiO}_{2}$ nanoparticles may diffuse to and occupy these spaces (for example, as illustrated in Figure $4 \mathrm{a}$ in the case of carbon-capped $\mathrm{Au} / \mathrm{TiO}_{2}$-based DSSC). Prior to assembling DSSCs, all films (i.e., pure $\mathrm{TiO}_{2}$ film (P25 film), P25 film coated with a layer of $\mathrm{Au} / \mathrm{TiO}_{2}$ nanoparticles, and P25 film coated with a layer of carbon-capped $\mathrm{Au} / \mathrm{TiO}_{2}$ nanoparticles) on FTO were immersed into $0.5 \mathrm{mM} \mathrm{N719}$ (Solaronix)/ethanol solution for $24 \mathrm{~h}$ at room temperature and then washed with ethanol and dried in air. The counter electrodes were prepared by the pyrolysis of a drop of $0.5 \mathrm{mM} \mathrm{H}_{2} \mathrm{PtCl}_{6} /$ isopropanol solution on the FTO at $400{ }^{\circ} \mathrm{C}$ for 20 min. Finally, DSSCs with films noted above as photoanode and Pt as counter electrode were assembled using a hot-melt film (SX1170-25; Solaronix) as spacer between the two electrodes with an active area of $0.1 \mathrm{~cm}^{2}$. A drop of redox electrolyte containing $0.60 \mathrm{M}$ BMIM-I, 0.03 $\mathrm{M} \mathrm{I}_{2}, 0.50 \mathrm{M}$ TBP, and $0.10 \mathrm{M}$ GTC in a mixture of acetonitrile and valeronitrile $(\mathrm{v} / \mathrm{v}=85 / 15)$ (No. ES-0004, www.io.li.tec.de, Germany) was injected between N719 dye-sensitized photoanode and Pt counter electrode.

2.3. Characterization. The size of PS-capped $\mathrm{Au} / \mathrm{TiO}_{2}$ nanoparticles were characterized by transmission electron microscopy (TEM, JEOL 100CX, FEI Tecnai F30). The crystalline phase of samples was examined by X-ray diffraction (XRD, X'pert PRO, Netherlands) and Raman spectroscopy (inVia Raman microscope, Renishaw). The external quantum efficiency (EQE) measurements were carried out using a photocurrent spectrum combination system (Zolix, China). The UV-vis absorption spectra of different types of photoanodes were measured by UV-Vis-NIR spectrophotometer (Cary 5000, USA). The current-voltage $(I-V)$ characteristics were measured using a Keithley model 2400 multisource meter under a simulated sunlight at 1 sun $\left(100 \mathrm{~mW} / \mathrm{cm}^{2}\right)$ calibrated with a Daystar Meter. The electrochemical impedance spectroscopy (EIS) measurements on DSSCs were carried out with a computer controlled electrochemical workstation (Zahner, Germany) with a frequency range of $10^{-1}$ to $10^{5} \mathrm{~Hz}$. Dye-loading was determined with a standard curve method. The dye was desorbed from samples using $0.02 \mathrm{M}$ $\mathrm{NaOH}$ in an aqueous and ethanol (1:1) mixed solution, and the absorbance of desorbed-dye solution was measured using a UV-vis spectrophotometer (UV-2600, SHIMADZU, Japan).

\section{RESULTS AND DISCUSSION}

Amphiphilic star-like P4VP-b-PtBA-b-PS triblock copolymer with a well-controlled length of each block (i.e., molecular weight) synthesized by ATRP of $4 \mathrm{VP}, t \mathrm{BA}$, and $\mathrm{St}$ in sequential order is shown in the upper left panel of Scheme 1. Compared with the micelles produced by self-assembly of linear amphiphilic block copolymers in selective solvent above critical micelle concentration, amphiphilic star-like block copolymers form stable spherical unimolecular micelle in solution. ${ }^{23}$ Due to covalent connections to a $\beta$-CD junction, star-like P4VP- $b$ PtBA- $b$-PS triblock copolymer possesses a robust star-like architecture to withstand internal (e.g., concentration) and external (e.g., $\mathrm{pH}$, temperature, etc.) variations. This contrasts sharply to dynamically stable micelles formed by linear amphiphilic block copolymers that may readily disintegrate in response to the change in concentration and the environmental triggers (e.g., solvent polarity, $\mathrm{pH}$, temperature, etc.). As a result, star-like P4VP-b-PtBA-b-PS triblock copolymer with amphiphilic character can be utilized as nanoreactor (i.e., template) to create plasmonic/semiconductor $\mathrm{Au} / \mathrm{TiO}_{2}$ core/ shell nanoparticles via localized coordination reactions between reactive functional groups (i.e., pyridine groups in P4VP blocks and carboxyl groups in PAA blocks obtained after the thermal hydrolysis of P $t$ BA blocks) of star-like P4VP- $b$-P $t$ BA- $b$-PS triblock copolymer and metal moieties of precursors (i.e., $\mathrm{Au}^{3+}$ in $\mathrm{HAuCl}_{4}$ and $\mathrm{Ti}^{4+}$ in TTIP) as discussed below.

Figure 1a,b compares TEM images of as-synthesized Au core and plasmonic/semiconductor $\mathrm{Au} / \mathrm{TiO}_{2}$ core/shell nanopar-
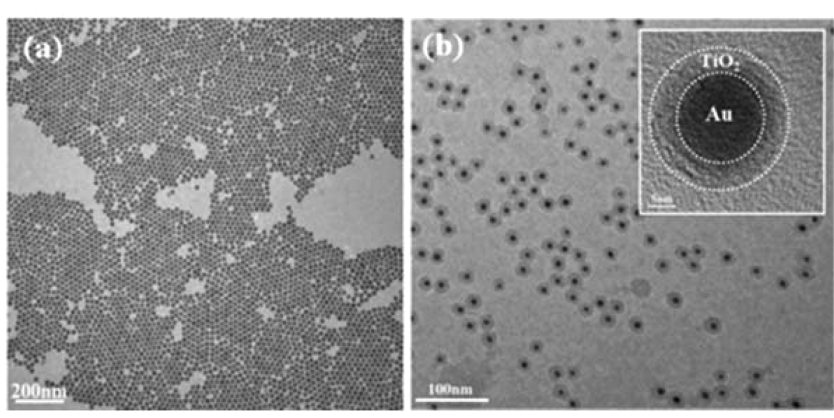

Figure 1. TEM images of (a) pure plasmonic Au core nanoparticles that are intimately capped with PtBA- $b$-PS chains on the surface and (b) plasmonic/semiconductor $\mathrm{Au} / \mathrm{TiO}_{2}$ core/shell nanoparticles tethered with PS chains on the surface. A HR-TEM of $\mathrm{Au} / \mathrm{TiO}_{2}$ core/shell nanoparticle is shown as an inset in (b) (scale bar $=5 \mathrm{~nm})$, where the diameter of $\mathrm{Au}$ core and the thickness of amorphous $\mathrm{TiO}_{2}$ are 15 and $5 \mathrm{~nm}$, respectively.

ticles crafted using star-like P4VP- $b$-P $t$ BA- $b$-PS triblock copolymers as template before and after the hydrolysis of central PtBA block, respectively. Clearly, the size of Au core and $\mathrm{Au} / \mathrm{TiO}_{2}$ core/shell nanoparticles are very uniform. The size distributions of $\mathrm{Au} / \mathrm{TiO}_{2}$ core/shell nanoparticles (i.e., histograms of $\mathrm{Au}$ core and $\mathrm{Au} / \mathrm{TiO}_{2}$ core/shell nanoparticles) are shown in Figure S1. The formation of monodisperse nanoparticles can be rationalized as follows. Dimethylformamide (DMF) and benzyl alcohol (BA) at DMF/BA = 9:1 by volume was used as mixed solvents for producing core/shell nanoparticles (see Experimental Section). As DMF is a good solvent for P4VP, PtBA, and PS, star-like P4VP- $b$-P $t$ BA- $b$-PS triblock copolymer would possess a fully expanded chain conformation when it is dissolved in pure DMF. On the other hand, BA is a good solvent for P4VP yet a poor solvent for PtBA and PS. Thus, in the DMF/BA = 9:1 mixed solvents, the outer PtBA- $b$-PS chains in star-like P4VP- $b$-P $t$ BA- $b$-PS triblock copolymers collapsed due to unfavorable interaction between PtBA- $b$-PS blocks and BA, while the inner P4VP chains retained the unperturbed conformation because of favorable interaction between P4VP blocks and BA. This led to the formation of uniform, structurally compact, spherical macromolecule comprising condensed PtBA- $b$-PS chains situated outside the coil-like P4VP chains. Consequently, the $\mathrm{Au}$ precursors, $\mathrm{HAuCl}_{4}$, were incorporated into the structurally compact space occupied by star-like P4VP blocks and transformed into $\mathrm{Au}$ nanoparticles (i.e., forming PS- $b$-PtBAcapped Au nanoparticles; upper central panel in Scheme 1) via preferential coordination interaction between $\mathrm{Au}^{3+}$ of $\mathrm{HAuCl}_{4}$ and pyridine groups of P4VP block (see Experimental in the Supporting Information). Subsequently, the hydrophobic PtBA blocks in PS- $b$-PtBA-capped Au nanoparticles were thermally hydrolyzed into hydrophilic PAA blocks in the mixed solvents 
of DMF and BA (volume ratio of $\mathrm{DMF} / \mathrm{BA}=9: 1$ ) (see Experimental Section and upper right panel in Scheme 1). Likewise, as BA is a good solvent for PAA but a poor solvent for PS, a well-defined PAA-containing regime covered with collapsed PS chains outside resulted due to the unfavorable interaction between outer PS chains and $\mathrm{BA}$. The $\mathrm{TiO}_{2}$ shell was formed through the localized coordination interaction between the metal moieties of $\mathrm{TiO}_{2}$ precursor, TTIP, and the carboxyl groups of PAA blocks (see Experimental Section and lower central panel in Scheme 1). Thus, PS-capped plasmonic/ semiconductor $\mathrm{Au} / \mathrm{TiO}_{2}$ core/shell nanoparticles were created.

It is not surprising that, as the molecular weights of P4VP and $\mathrm{P} t \mathrm{BA}$ are $13 \mathrm{k}$ and $8.5 \mathrm{k}$, respectively, the resulting core/shell nanoparticles exhibited relatively larger Au core diameter $(\sim 15$ nm) and slightly smaller $\mathrm{TiO}_{2}$ shell thickness $(\sim 5 \mathrm{~nm})$, characterized by high-resolution transmission electron microscopy (HR-TEM) in the inset of Figure $1 \mathrm{~b}$. Intriguingly, the surfaces of $\mathrm{Au}$ core and $\mathrm{Au} / \mathrm{TiO}_{2}$ core/shell nanoparticles are permanently covered by PtBA-PS and PS chains, respectively, which were originally covalently connected to inner P4VP chains and central PtBA chains of star-like P4VP- $b$-P $t$ BA- $b$-PS triblock copolymer templates, thereby circumventing the issues of possible absorption and desorption of surface ligands during the nanoparticle storage. Strikingly, the resulting nanoparticles showed an excellent dispersion in nonpolar solvents and possessed a superior long-term stability. It is also worth noting that the growth of shell material did not rely on the lattice match with that of core material as it was formed by independently templating with central hydrophilic PAA blocks (i.e., the coordination interaction between the precursors of shell material and the carboxyl groups of PAA blocks). This dispensed with the need for epitaxial growth that is often required to form high-quality core/shell nanoparticles.

It is interesting to note that X-ray diffraction patterns of asprepared $\mathrm{Au} / \mathrm{TiO}_{2}$ nanoparticles (Figure 2a; capped with PS chains on the surface) showed that only characteristic peaks of $\mathrm{Au}$ corresponding to (111), (200), (220), and (311) lattice planes appeared, suggesting that the $\mathrm{TiO}_{2}$ shell was amorphous. The Raman spectroscopy measurement further substantiated the amorphous nature of the $\mathrm{TiO}_{2}$ shell (Figure 3). In the meantime, four peaks originated from PS chains permanently

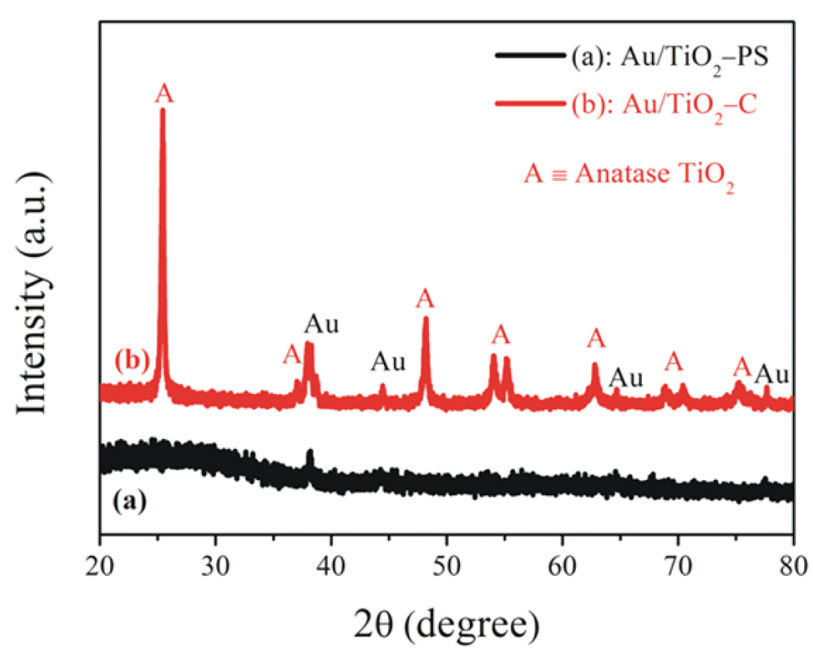

Figure 2. X-ray diffraction profiles of (a) as-prepared PS-capped $\mathrm{Au} /$ $\mathrm{TiO}_{2}$ nanoparticles and (b) after thermal annealing at $500{ }^{\circ} \mathrm{C}$ under $\mathrm{Ar}$ atmosphere. (a)
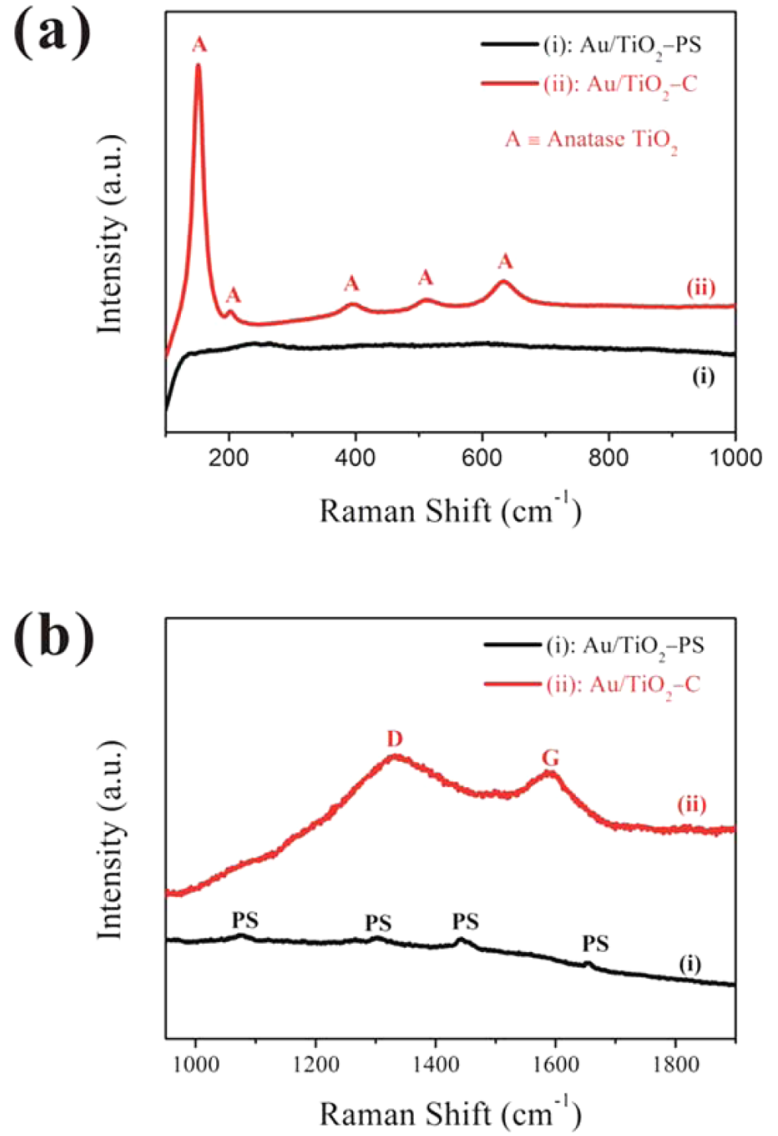

Figure 3. Raman spectra of (i) as-prepared PS-capped $\mathrm{Au} / \mathrm{TiO}_{2}$ nanoparticles (i.e., $\mathrm{Au} / \mathrm{TiO}_{2}-\mathrm{PS}$ ) and (ii) after thermal annealing at $500{ }^{\circ} \mathrm{C}$ under $\mathrm{Ar}$ atmosphere (i.e., forming $\mathrm{Au} / \mathrm{TiO}_{2}-\mathrm{C}$ ). Each spectrum was divided into two regions for clarity: (a) from 1000 to $100 \mathrm{~cm}^{-1}$; (b) from 1900 to $900 \mathrm{~cm}^{-1}$. The peaks of anatase phase of $\mathrm{TiO}_{2}$ were at $152,202,395,510$, and $636 \mathrm{~cm}^{-1}$; the peaks of PS were at $1075,1303,1443$, and $1652 \mathrm{~cm}^{-1}$; the peaks of D and G of carbon were at 1332 and $1595 \mathrm{~cm}^{-1}$, respectively.

and chemically linked to $\mathrm{TiO}_{2}$ were seen (Figure $3 \mathrm{~b}$ ), where the $1652,1443,1303$, and $1075 \mathrm{~cm}^{-1}$ peaks can be assigned to the $\mathrm{C}=\mathrm{C}$ stretching, $19 \mathrm{~b}$ ring $\mathrm{C}-\mathrm{C}$ stretching, $\mathrm{C}-\mathrm{H}$ in-plane bending, and $18 \mathrm{~b} \mathrm{C}-\mathrm{H}$ in-plane bending modes, respectively. ${ }^{26}$ Amorphous $\mathrm{TiO}_{2}$ shell was converted into anatase form after sintering at $500{ }^{\circ} \mathrm{C}$ under Ar atmosphere as evidenced by XRD (Figure 2) and Raman spectroscopy (Figure 3a) studies. The emergence of X-ray diffraction peaks corresponding to (101), (103), (004), (112), (200), (105), (211), (204), (116), (220), and (215) crystalline planes well-matched the typical anatase $\mathrm{TiO}_{2}$ phase (JCPDS file No. 01-073-1764).

The Raman spectra also displayed the characteristic bands of anatase $\mathrm{TiO}_{2}$ at $636,510,395,202$, and $152 \mathrm{~cm}^{-1}$. Meanwhile, compelling evidence from two distinct vibration modes of carbon known as D band and G band appearing in the Raman measurement further confirmed that all PS chains situated outside the $\mathrm{TiO}_{2}$ shell surface were converted into carbon (Figure $3 \mathrm{~b}$ ). The appearance of D band and G band can be attributed to the alternating ring stretch vibration and $\mathrm{sp}^{2}$ stretch vibration, respectively, and the intensity of $\mathrm{D}$ peak was higher than $G$ peak, corresponding to carbon rings resulting from carbonization of benzene rings in PS chains. ${ }^{27-29}$ We note that, for as-prepared $\mathrm{Au} / \mathrm{TiO}_{2}$ nanoparticles sintered at $500{ }^{\circ} \mathrm{C}$ in air, the amorphous $\mathrm{TiO}_{2}$ shell was also converted into 
anatase and no carbon was formed, as clearly evidenced by the Raman measurement (Figure S2).

$\mathrm{Au} / \mathrm{TiO}_{2}$ nanoparticles composed of plasmonic core and semiconductor shell were then exploited to enhance light harvesting in DSSCs by coating a thin layer of $\mathrm{Au} / \mathrm{TiO}_{2}$ nanoparticles on the top of conventional $\mathrm{TiO}_{2}$ nanoparticle film photoanode prepared by blade-coating $\mathrm{P} 25$ paste. Hereafter, $\mathrm{TiO}_{2}$ nanoparticle film is referred to as $\mathrm{P} 25$ film. We note that, when $\mathrm{Au} / \mathrm{TiO}_{2}$ nanoparticles were spin-coated on the P25 film surface from PS-capped $\mathrm{Au} / \mathrm{TiO}_{2}$ nanoparticle toluene solution, the layer of $\mathrm{Au} / \mathrm{TiO}_{2}$ nanoparticles was hardly seen by naked eyes. However, this thin layer can be clearly observed when nanoparticles were deposited on the FTO glass under the same condition and approximately a monolayer thick. The P25 films integrated with such thin $\mathrm{Au} / \mathrm{TiO}_{2}$ nanoparticle layer were annealed in air and $\mathrm{Ar}$ at $500{ }^{\circ} \mathrm{C}$, respectively, and then used as photoanodes for assembling DSSCs. The currentvoltage $(I-V)$ characteristics of devices under a simulated sunlight at 1 sun $\left(100 \mathrm{~mW} / \mathrm{cm}^{2}\right)$ with and without the incorporation of $\mathrm{Au} / \mathrm{TiO}_{2}$ nanoparticles were measured as shown in Figure 4. Tables S1-S4 summarize the device performance of the resulting DSSCs using different photo-

(a)

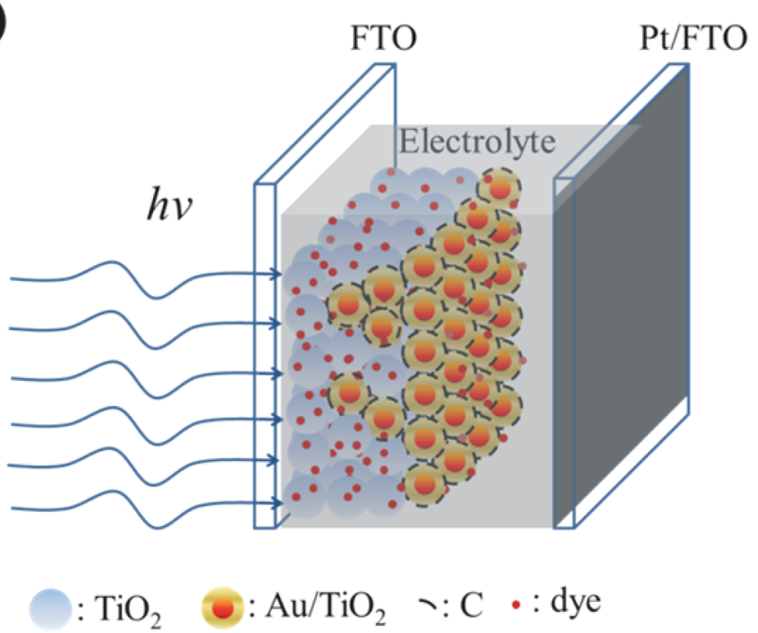

(b)

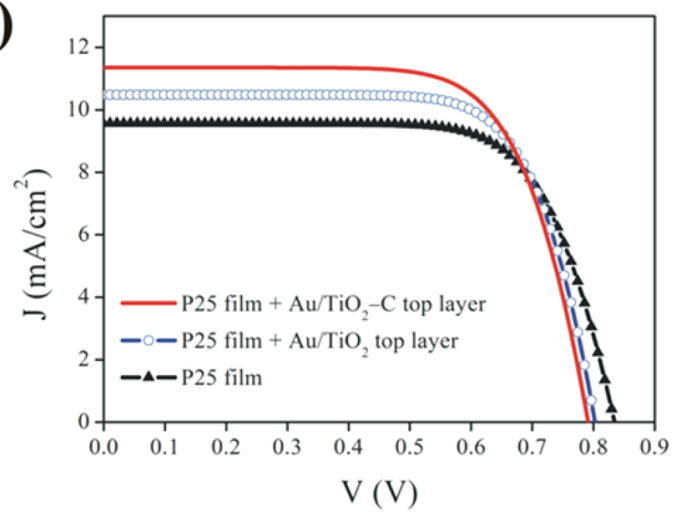

Figure 4. (a) Schematic illustration of DSSC assembled with a layer of $\mathrm{Au} / \mathrm{TiO}_{2}-\mathrm{C}$ on the top of the P25 film as photoanode. As there may exist some possible unoccupied spaces due to solvent evaporation after blade-coating of P25 film, $\mathrm{Au} / \mathrm{TiO}_{2}-\mathrm{C}$ nanoparticles may partially deposit and occupy these spaces inside the P25 film as shown in the schematic. (b) $J-V$ characteristics of DSSCs assembled by capitalizing on three different types of photoanodes. anodes. Clearly, compared to the device with P25 film solely used as photoanode, by employing photoanodes comprising a bottom P25 film and a top plasmonic/semiconductor $\mathrm{Au} / \mathrm{TiO}_{2}$ nanoparticles layer that was either annealed in air (i.e., naked $\mathrm{Au} / \mathrm{TiO}_{2}$ nanoparticles) or $\mathrm{Ar}$ (i.e., carbon-capped $\mathrm{Au} / \mathrm{TiO}_{2}$ nanoparticles; denoted $\left.\mathrm{Au} / \mathrm{TiO}_{2}-\mathrm{C}\right)$, the short-circuit current density, $J_{\mathrm{SC}}$, of DSSCs increased. However, the open circuit voltage, $V_{\mathrm{OC}}$, decreased slightly while the fill factor, $\mathrm{FF}$, remained similar. The incorporation of naked $\mathrm{Au} / \mathrm{TiO}_{2}$ nanoparticle into the P25 film as photoanode resulted in an improved device performance (i.e., from $5.67 \%$ in pure P25based device to $6.09 \%$ in $\mathrm{Au} / \mathrm{TiO}_{2}$-based device, representing an $7.4 \%$ increase) which can be attributed to surface plasmonenabled light harvesting enhancement. Specifically, with the addition of a naked $\mathrm{Au} / \mathrm{TiO}_{2}$ layer, a $10 \%$ increase in $J_{\mathrm{SC}}$ was found (from $9.56 \mathrm{~mA} / \mathrm{cm}^{2}$ in a pure P25 film-based device to $\left.10.41 \mathrm{~mA} / \mathrm{cm}^{2}\right)$. In general, the high current density is due to a large amount of dye-loading. Comparing the three different photoanodes, the dye-loading of a naked $\mathrm{Au} / \mathrm{TiO}_{2}$-incorporated device was only slightly higher than the pure P25-based device (an $\sim 7 \%$ increase; Table S1). Thus, the increased $J_{S C}$ may partly result from the surface plasmon enhancement of $\mathrm{Au}$ core in plasmonic/semiconductor $\mathrm{Au} / \mathrm{TiO}_{2}$ core/shell nanoparticles. The external quantum efficiency (EQE) measurement showed a broadband EQE enhancement in the wavelength range of $430-650 \mathrm{~nm}$, especially from 520 to $530 \mathrm{~nm}$ (Figure S3). Meanwhile, the UV-vis absorption spectra of three different types of N719-loaded photoanodes were measured and displayed an absorption enhancement in the same wavelength range (Figure S4). Moreover, the UV-vis absorption spectra of PS-PtBA-capped $\mathrm{Au}$ and PS-capped $\mathrm{Au} / \mathrm{TiO}_{2}$ nanoparticle toluene solution are shown in Figure S5. The absorption maxima at 522 and $531 \mathrm{~nm}$ were clearly evident due to the plasmonic absorption of $\mathrm{Au}$ core, which matched well with the wavelength range of EQE and absorption enhancement. Typically, for a $15 \mathrm{~nm} \mathrm{Au}$ nanoparticle, the plasmonic peak appears at about $520 \mathrm{~nm} .{ }^{4}$ Obviously, the peak in the PS-capped $\mathrm{Au} / \mathrm{TiO}_{2}$ nanoparticles was red-shifted. This is not surprising as the SPR extinction wavelength is sensitive to the change of dielectric environment and the $\mathrm{TiO}_{2}$ shell having a high dielectric constant changed the local dielectric environment of the $\mathrm{Au}$ core, ${ }^{30}$ leading to a red-shift of plasmonic absorption.

It is well-known that $V_{\mathrm{OC}}$ depends on the energy level difference between the Fermi level of semiconductor photoanode and the oxidation-reduction potential of electrolyte. $V_{\mathrm{OC}}$ decreased from $0.829 \mathrm{~V}$ in the pure P25 film-based device to $0.801 \mathrm{~V}$ in the device employing the combined P25 film and $\mathrm{Au} / \mathrm{TiO}_{2}$ nanoparticles as photoanode. This can be understood as follows. The Fermi-level of $\mathrm{Au}$ is lower than that of $\mathrm{TiO}_{2}{ }^{31}$ When $\mathrm{TiO}_{2}$ and Au were in contact, their Fermi levels became equal. This led to a reduced Fermi level of $\mathrm{TiO}_{2}$ compared to the pure P25 case and ultimately a decreased $V_{\mathrm{OC}}$.

In comparison to the sample (i.e., PS-capped $\mathrm{Au} / \mathrm{TiO}_{2}$ nanoparticles deposited on the P25 film surface) annealed in air, the sample annealed in Ar exhibited a higher $J_{\mathrm{SC}}$ and lower $V_{\mathrm{OC}}$. The difference between these two samples was that the outer insulating PS chains on the surface of $\mathrm{Au} / \mathrm{TiO}_{2}$ nanoparticles were carbonized in $\mathrm{Ar}$ and coated on the nanoparticle surface as revealed by the Raman measurement (Figure 3). Because of the emergence of conductive carbon on the surface, the Fermi level of photoanodes further reduced, resulting in a lowered $V_{\mathrm{OC}}(0.785 \mathrm{~V}$ only $)$. In contrast, $J_{\mathrm{SC}}$ 
increased up to $11.32 \mathrm{~mA} / \mathrm{cm}^{2}$, representing $8.7 \%$ and $18.4 \%$ increases compared to the air-annealed sample and pure P25 sample, respectively. The UV-Vis absorption spectra of N719loaded photoanode annealed in Ar showed that the light absorption was slightly higher than the pure P25 sample and lower than the air-annealed sample (Figure S4). However, the EQE measurement showed an obvious EQE enhancement below $600 \mathrm{~nm}$ (Figure S3). Thus, the carbonized material may play a key role in the photoelectron collection efficiency. It has been demonstrated that the use of carbon materials coupled with $\mathrm{TiO}_{2}$ photoanode can increase the speed of electron transport and thus reduce the charge recombination. ${ }^{32,33}$ In order to elucidate the charge transfer properties, electrochemical impedance spectroscopy (EIS) measurements were performed. Figure 5a,b shows the Nyquist plots and the EIS model for DSSC, respectively. There were two semicircles in the plots (Figure 5a), reflecting two interfaces in DSSC. The small semicircle at high frequency corresponded to the charge transfer at the Pt counter electrode/electrolyte interface, where $R_{1}$ is the charge-transfer resistance at the interface and $\mathrm{CPE}_{1}$ is the interfacial capacitance in the EIS model. The second large semicircle was related to the charge transfer at the dyesensitized photoanode/electrolyte interface, where $R_{2}$ and $\mathrm{CPE}_{2}$ are charge transfer resistance at the interface and chemical capacitance representing the change of electron density as a function of the Fermi level, respectively, in the EIS model. The starting point on the left of the small semicircle correlates to the overall electron transport resistance on the photoanode. After the carbonation of PS chains capped on the surface of $\mathrm{Au} / \mathrm{TiO}_{2}$ nanoparticles, a layer of carbon surrounding $\mathrm{Au} / \mathrm{TiO}_{2}$ nanoparticles was formed, that is, $\mathrm{Au} / \mathrm{TiO}_{2}-\mathrm{C}$. As a result, electrons can quickly be transported on the $\mathrm{Au} / \mathrm{TiO}_{2}-\mathrm{C}$ nanoparticle surface that was in close contact with the P25 film and be collected by the FTO-coated transparent substrate. As shown in Table $\mathrm{S} 1$, the $\mathrm{Au} / \mathrm{TiO}_{2}-\mathrm{C}$-based DSSC had the lowest electron transport resistance, $R_{S}$. Meanwhile, the charge transfer resistance, $R_{2}$, of naked- $\mathrm{Au} / \mathrm{TiO}_{2^{-}}$and $\mathrm{Au} / \mathrm{TiO}_{2}-\mathrm{C}$ based DSSCs was slightly smaller than that of the pure P25based device, suggesting that two devices with two integrated photoanodes had a faster charge transfer rate than that which was fabricated with pure P25 photoanode. However, as the carbon layer was in direct contact with the electrolyte, this increased the charge recombination rate in $\mathrm{Au} / \mathrm{TiO}_{2}-\mathrm{C}$-based DSSC, leading to the increase of charge transfer resistance, $R_{2}$, under illumination. As a result, $R_{2}$ of the $\mathrm{Au} / \mathrm{TiO}_{2}-\mathrm{C}$-based device was slightly larger than that of the naked-Au/ $/ \mathrm{TiO}_{2}$-based DSSC. The electron lifetime, $\tau_{\mathrm{n}}$, which is related to both electron transport and charge transfer, was calculated from the Bode phase plot according to the equation, $\tau_{\mathrm{n}}=1 /\left(2 \pi f_{\mathrm{p}}\right)$, where $f_{\mathrm{p}}$ is the peak frequency with the highest phase (Figure $5 c, d)$. As shown in Figure $5 d$, the peak position of $\mathrm{Au} / \mathrm{TiO}_{2}-$ C-based DSSC was at the low frequency region, reflecting a long electron lifetime, $\tau_{\mathrm{n}}$, in light of the equation shown above (Table S1). The presence of carbon layer on the $\mathrm{Au} / \mathrm{TiO}_{2}$ nanoparticles surface shortened the electron transport time and increased the electron lifetime, thereby increasing the electron collection efficiency. As a result, the $\mathrm{Au} / \mathrm{TiO}_{2}-\mathrm{C}$-based DSSC displayed a higher $J_{S C}$ and an improved power conversion efficiency, PCE. Moreover, when compared to the P25-based device, DSSC assembled by incorporating carbonized $\mathrm{Au} / \mathrm{TiO}_{2}$ nanoparticles on the top of the P25 film as photoanode exhibited a largely improved JSC (from 9.56 to $11.32 \mathrm{~mA} / \mathrm{cm}^{2}$; an $18.4 \%$ increase (Table S1)) and PCE (from $5.67 \%$ to $6.44 \%$; (a)

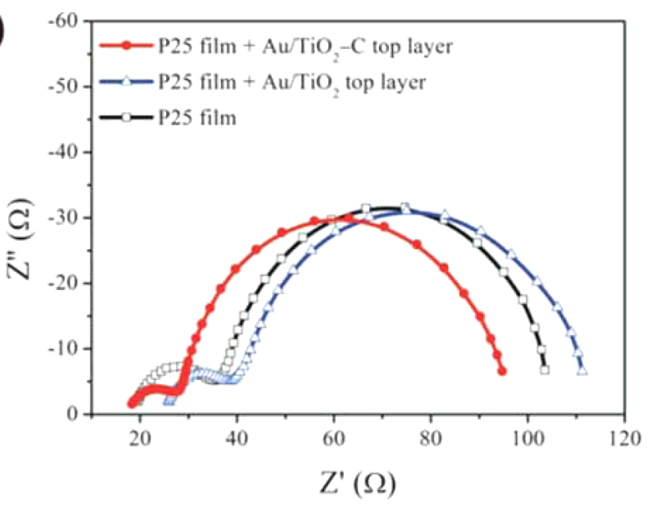

(b)

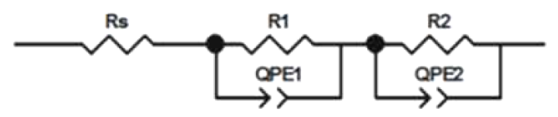

(c)

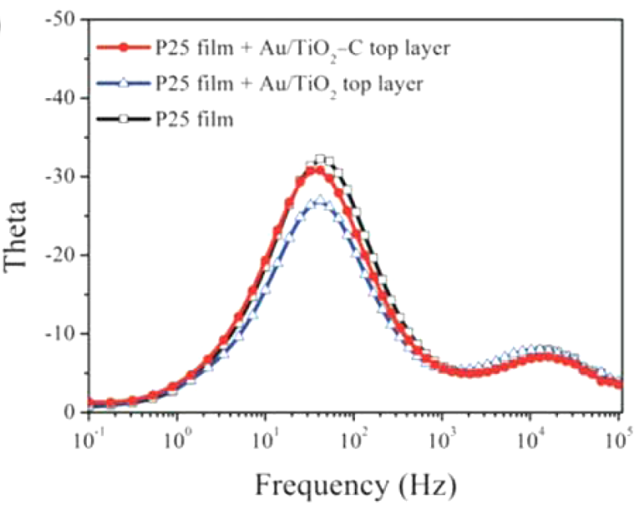

(d)

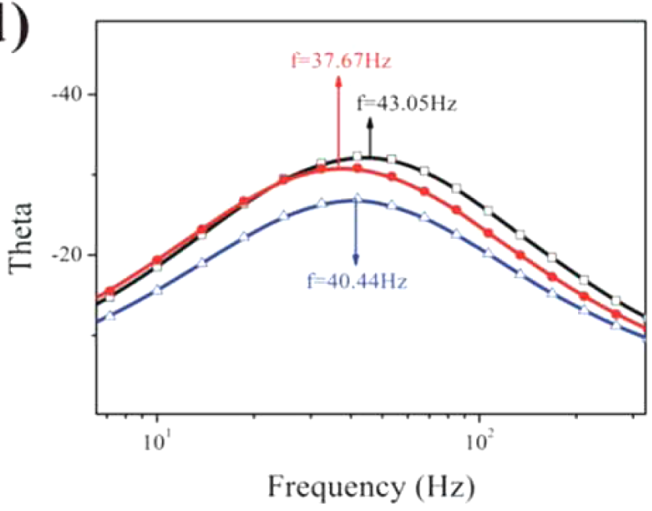

Figure 5. Electrochemical impedance spectroscopy (EIS) measurements on DSSCs assembled using three different photoanodes at the $100 \mathrm{~mW} / \mathrm{cm}^{2}$ illumination. (a) Nyquist plots, (b) EIS model, and (c) Bode phase plots. (d) Close-up of (c) in the low frequency range.

a $13.6 \%$ increase (Table S1)), respectively. The improvement in $J_{S C}$ and PCE was a direct consequence of the synergy of surface plasmon-enabled light harvesting enhancement of $\mathrm{Au}$ core and fast charge transport promoted by carbon situated on the $\mathrm{Au} / \mathrm{TiO}_{2}$ nanoparticles surface formed by thermal annealing of PS-capped $\mathrm{Au} / \mathrm{TiO}_{2}$ nanoparticles in $\mathrm{Ar}$ atmosphere. 


\section{CONCLUSION}

In summary, the use of tailor-made amphiphilic star-like P4VP$b$-PtBA-b-PS triblock copolymer as nanoreactor stands out as an extremely robust route to creating monodisperse plasmonic/ semiconductor $\mathrm{Au} / \mathrm{TiO}_{2}$ core/shell nanoparticles with wellcontrolled core diameter and shell thickness. $\mathrm{Au} / \mathrm{TiO}_{2}$ core/ shell nanoparticles can be well dispersed in nonpolar solvents as the nanoparticle surface was chemically and permanently linked with outer hydrophobic PS chains from star-like triblock copolymer. These PS-capped plasmonic/semiconductor core/ shell nanoparticles were then deposited on the $\mathrm{P} 25 \mathrm{TiO}_{2}$ film surface and exploited as photoanode in DSSCs. Owing largely to $\mathrm{Au}$ core plasmon-enhanced light absorption, an improved power conversion efficiency was the result. Quite intriguingly, when PS chains on the $\mathrm{Au} / \mathrm{TiO}_{2}$ nanoparticle surface were transformed into carbon by thermally annealing PS-capped $\mathrm{Au} /$ $\mathrm{TiO}_{2}$ nanoparticles in an inert environment, in comparison to the P25-based device, the short-circuit current density and power conversion efficiency of DSSC assembled by depositing such carbonized $\mathrm{Au} / \mathrm{TiO}_{2}$ nanoparticles on the top of the P25 film as photoanode increased by $18.4 \%$ and $13.6 \%$, respectively. The synergy of surface plasmon-enabled light harvesting enhancement of Au core and faster charge transport promoted by conductive carbon formed on the $\mathrm{Au} / \mathrm{TiO}_{2}$ nanoparticle surface yielded the improved device efficiency.

\section{ASSOCIATED CONTENT}

\section{S Supporting Information}

The Supporting Information is available free of charge on the ACS Publications website at DOI: 10.1021/acs.chemmater.5b01422.

The size distribution of Au core nanoparticles solely and $\mathrm{Au} / \mathrm{TiO}_{2}$ core/shell nanoparticles. The Raman spectra of naked $\mathrm{Au} / \mathrm{TiO}_{2}$ nanoparticles. The EQE and EQE enhancement of the optimized DSSCs assembled by capitalizing on three different types of photoanodes. UVVis absorption spectra of N719-loaded three different types of photoanodes. UV-Vis absorption spectra of PScapped $\mathrm{TiO}_{2}$ nanoparticles, PS- $b$-P $t$ BA-capped Au nanoparticles, and PS-capped $\mathrm{Au} / \mathrm{TiO}_{2}$ core/shell nanoparticles in toluene, respectively. Summary of device performance of DSSCs by employing different types of photoanodes. (PDF)

\section{AUTHOR INFORMATION}

\section{Corresponding Authors}

*E-mail: zhiqun.lin@mse.gatech.edu.

*E-mail: cjlin@xmu.edu.cn.

\section{Notes}

The authors declare no competing financial interest.

\section{ACKNOWLEDGMENTS}

D.Z., M.W., and C.L. gratefully acknowledge the financial support from the China Scholarship Council. This work is supported by the Air Force Office of Scientific Research (FA9550-13-1-0101 and MURI FA9550-14-1-0037) (Z.L.), the National Natural Science Foundation of China (51072170 and 21021002) and the National Basic Research Program of China (2012CB932900) (C.L.), and Minjiang Scholar Program (Z.L.).

\section{REFERENCES}

(1) Pang, X.; Zhao, L.; Han, W.; Xin, X.; Lin, Z. A general and robust strategy for the synthesis of nearly monodisperse colloidal nanocrystals. Nat. Nanotechnol. 2013, 8, 426-431.

(2) Zhang, J.; Tang, Y.; Lee, K.; Ouyang, M. Nonepitaxial growth of hybrid core-shell nanostructures with large lattice mismatches. Science 2010, 327, 1634-1638.

(3) Sun, Y. G.; Xia, Y. N. Shape-controlled synthesis of gold and silver nanoparticles. Science 2002, 298, 2176-2179.

(4) Yu, H.; Chen, M.; rice, P. M.; Wang, S. X.; White, R. L.; Sun, S. Dumbbell-like bifunctional Au-Fe3O4 nanoparticles. Nano Lett. 2005, 5, 379-382.

(5) Yella, A.; Lee, H. W.; Tsao, H. N.; Yi, C. Y.; Chandiran, A. K.; Nazeeruddin, M. K.; Diau, E. W. G.; Yeh, C. Y.; Zakeeruddin, S. M.; Gratzel, M. Porphyrin-Sensitized Solar Cells with Cobalt (II/III)Based Redox Electrolyte Exceed 12\% Efficiency. Science 2011, 334, 629-634.

(6) O’Regan, B.; Gratzel, M. A low-cost, high-efficiency solar cell based on dye-sensitized colloidal TiO2 films. Nature 1991, 353, 737740.

(7) Wang, J.; Lin, Z. Q. Dye sensitized TiO2 nanotube solar cell with markedly enhanced performance via rational surface engineering. Chem. Mater. 2010, 22, 579-584.

(8) Xin, X.; He, M.; Han, W.; Jung, J.; Lin, Z. Low-cost CZTS counter electrodes for high-efficiency dye sensitized solar cells. Angew. Chem., Int. Ed. 2011, 50, 11739-11742.

(9) Ye, M.; Xin, X.; Lin, C. J.; Lin, Z. High efficiency dye-sensitized solar cells based on hierarchically structured nanotubes. Nano Lett. 2011, 11, 3214-3220.

(10) Ye, M.; Zheng, D.; Lv, M.; Chen, C.; Lin, C.; Lin, Z. Hierarchically structured nanotubes for highly efficient dye-sensitized solar cells. Adv. Mater. 2013, 25, 3039-3044.

(11) Hagfeldt, A.; Boschloo, G.; Sun, L.; Kloo, L.; Pettersson, H. Dye-Sensitized Solar Cells. Chem. Rev. 2010, 110, 6595-6663.

(12) Mathew, S.; Yella, A.; Gao, P.; Humphry-Baker, R.; Curchod, B. F. E.; Ashari-Astani, N.; Tavernelli, I.; Rothlisberger, U.; Nazeeruddin, M. K.; Grätzel, M. Dye-sensitized solar cells with $13 \%$ efficiency achieved through the molecular engineering of porphyrin sensitizers. Nat. Chem. 2014, 6, 242-247.

(13) Ye, M.; Liu, H.; Lin, C. J.; Lin, Z. Hierarchical Rutile TiO2 Flower Cluster-Based High Efficiency Dye-Sensitized Solar Cells via Direct Hydrothermal Growth on Conducting Substrates. Small 2013, 9, 312-321.

(14) Meyer, G. J. The 2010 Millennium Technology Grand Prize: Dye-Sensitized Solar Cells. ACS Nano 2010, 4, 4337-4343.

(15) Qi, J.; Dang, X.; Hammond, P. T.; Belcher, A. M. Highly Efficient Plasmon-Enhanced Dye-Sensitized Solar Cells through Metal@Oxide Core-Shell Nanostructure. ACS Nano 2011, 5, $7108-7116$.

(16) Brown, M. D.; Suteewong, T.; Kumar, R. S. S.; D’Innocenzo, V.; Petrozza, A.; Lee, M. M.; Wiesner, U.; Snaith, H. J. Plasmonic DyeSensitized Solar Cells Using Core-Shell Metal-Insulator Nanoparticles. Nano Lett. 2011, 11, 438-445.

(17) Jang, Y. H.; Jang, Y. J.; Kochuveedu, S. T.; Byun, M.; Lin, Z.; Kim, D. H. Plasmonic dye-sensitized solar cells incorporated with Au$\mathrm{TiO} 2$ nanostructures with tailored configurations. Nanoscale 2014, 6, $1823-1832$

(18) Song, M.-k.; Rai, P.; Ko, K.-J.; Jeon, S.-H.; Chon, B.-S.; Lee, C.H.; Yu, Y.-T. Synthesis of TiO2 hollow spheres by selective etching of $\mathrm{Au} @ \mathrm{TiO} 2$ core-shell nanoparticles for dye sensitized solar cell applications. RSC Adv. 2014, 4, 3529-3535.

(19) Hou, W. B.; Pavaskar, P.; Liu, Z. W.; Theiss, J.; Aykol, M.; Cronin, S. B. Plasmon resonant enhancement of dye sensitized solar cells. Energy Environ. Sci. 2011, 4, 4650-4655.

(20) Dang, X.; Qi, J.; Klug, M. T.; Chen, P.-Y.; Yun, D. S.; Fang, N. X.; Hammond, P. T.; Belcher, A. M. Tunable Localized Surface Plasmon-Enabled Broadband Light-Harvesting Enhancement for High-Efficiency Panchromatic Dye-Sensitized Solar Cells. Nano Lett. 2013, 13, 637-642. 
(21) Standridge, S. D.; Schatz, G. C.; Hupp, J. T. Distance Dependence of Plasmon-Enhanced Photocurrent in Dye-Sensitized Solar Cells. J. Am. Chem. Soc. 2009, 131, 8407-8409.

(22) Adhyaksa, G. W. P.; Baek, S.-W.; Lee, G. I.; Lee, D. K.; Lee, J.Y.; Kang, J. K. Coupled Near- and Far-Field Scattering in Silver Nanoparticles for High-Efficiency, Stable, and Thin Plasmonic DyeSensitized Solar Cells. ChemSusChem 2014, 7, 2461-2468.

(23) Pang, X.; Zhao, L.; Akinc, M.; Kim, J. K.; Lin, Z. Novel amphiphilic multi-arm, star-like block copolymers as unimolecular micelles. Macromolecules 2011, 44, 3746-3752.

(24) Pang, X.; Zhao, L.; Feng, C.; Lin, Z. Q. Novel amphiphilic multiarm, star-like coil-rod diblock copolymers via a combination of click chemistry with living polymerization. Macromolecules 2011, 44, 71767183.

(25) Pang, X.; Feng, C.; Xu, H.; Han, W.; Xin, X.; Xia, H.; Lin, Z. Unimolecular micelles composed of inner coil-like blocks and outer rod-like blocks crafted by combination of living polymerization with click chemistry. Polym. Chem. 2014, 5, 2747-2755.

(26) Sears, W. M.; Hunt, J. L.; Stevens, J. R. Raman scattering from polymerizing styrene. I. Vibrational mode analysis. J. Chem. Phys. 1981, $75,1589-1598$.

(27) Jawhari, T.; Roid, A.; Casado, J. Raman spectroscopic characterization of some commercially available carbon black materials. Carbon 1995, 33, 1561-1565.

(28) Cuesta, A.; Dhamelincourt, P.; Laureyns, J.; Martínez-Alonso, A.; Tascón, J. M. D. Raman microprobe studies on carbon materials. Carbon 1994, 32, 1523-1532.

(29) Schwan, J.; Ulrich, S.; Batori, V.; Ehrhardt, H.; Silva, S. R. P. Raman spectroscopy on amorphous carbon films. J. Appl. Phys. 1996, 80, 440-447.

(30) Willets, K. A.; Van Duyne, R. P. Localized surface plasmon resonance spectroscopy and sensing. Annu. Rev. Phys. Chem. 2007, 58, 267-297.

(31) Subramanian, V.; Wolf, E. E.; Kamat, P. V. Catalysis with TiO2/ Gold Nanocomposites. Effect of Metal Particle Size on the Fermi Level Equilibration. J. Am. Chem. Soc. 2004, 126, 4943-4950.

(32) Jang, Y. H.; Xin, X.; Byun, M.; Jang, Y. J.; Lin, Z.; Kim, D. H. An Unconventional Route to High-Efficiency Dye-Sensitized Solar Cells via Embedding Graphitic Thin Films into TiO2 Nanoparticle Photoanode. Nano Lett. 2012, 12, 479-485.

(33) Dembele, K. T.; Selopal, G. S.; Soldano, C.; Nechache, R.; Rimada, J. C.; Concina, I.; Sberveglieri, G.; Rosei, F.; Vomiero, A. Hybrid Carbon Nanotubes-TiO2 Photoanodes for High Efficiency Dye-Sensitized Solar Cells. J. Phys. Chem. C 2013, 117, 14510-14517. 